\title{
Limites e possibilidades da auditoria em enfermagem e seus aspectos teóricos e práticos
}

\author{
Limits and possibilities of the nursing auditory and its theoretical and practical aspects \\ Límites y posibilidades de la auditoría en enfermería y sus aspectos teóricos y prácticos
}

\section{Maria Verônica Sales da Silva', Lucilane Maria Sales da Silva", Hanna Helen Matos Dourado"II, Adail Afrânio Marcelino do Nascimento ${ }^{\mathrm{IV}}$, Thereza Maria Magalhães Moreirav}

\author{
' Programa Pesquisa para o Sistema Único de Saúde (PPSUS), FUNCAP/MINISTÉRIO DA SAÚDE/CNPQ. \\ Fortaleza-CE, Brasil. \\ "Universidade Estadual do Ceará, Curso de Graduação em Enfermagem. Fortaleza-CE, Brasil. \\ I" Universidade Estadual do Ceará, Curso de Graduação em Enfermagem (Graduando), Bolsista PPSUS. Fortaleza-CE, Brasil. \\ "N Universidade Estadual do Ceará, Programa de Doutorado em Saúde Coletiva UFC/UECE (Doutorando). \\ Fortaleza-CE, Brasil. \\ ${ }^{v}$ Universidade Estadual do Ceará, Programa de Doutorado em Saúde Coletiva UFC/UECE. Fortaleza-CE, Brasil.
}

Submissão: 04-01-2011 Aprovação: 10-08-2012

\section{RESUMO}

Este artigo tem o objetivo de fazer uma análise crítico-reflexiva a respeito da auditoria em enfermagem com análise dos limites e possibilidades e seus aspectos teóricos e práticos. A auditoria em enfermagem, na atualidade, é exercida e difundida nas instituições públicas e privadas, objetivando minimizar desperdício de materiais, medicamentos, equipamentos e recursos humanos. Ressalta-se a importância do registro da equipe de enfermagem, fundamental ao processo de auditoria. Ao profissional enfermeiro em auditoria compete a garantia da qualidade da assistência prestada ao usuário. São muitos os desafios a enfrentar para o desenvolvimento da auditoria em enfermagem, tais como a descoberta de uma identidade profissional e a integração com auditores enfermeiros de todo o país, entre outros.

Descritores: Auditoria de Enfermagem; Processo de Trabalho; Qualidade da Assistência à Saúde.

\section{ABSTRACT}

This article aims to make a critical-reflexive analysis about the nursing auditory, observing its limits and possibilities as well as its theoretical and practical aspects. The nursing auditory, nowadays, is practiced and advertised in public and private institutions, aiming to minimize material, medication, equipment and human resources loss. It is important to mention the presence of the nursing group which was fundamental to the auditory process. The professional nurse in auditory is responsible for the quality of the assistance directed towards the patient. There are many challenges involving the development of the nursing auditory, such as the discovery of a professional identity and the integration with auditory nurses all over the country, among others.

Key words: Nursing Auditory; Working Process; Quality of Health Care.

\section{RESUMEN}

Este artículo tiene como objetivo hacer un análisis crítico - reflexivo a respecto de la auditoría en enfermería con análisis de los límites y posibilidades y sus aspectos teóricos y prácticos. La auditoría en enfermería, en la actualidad, es ejercida y difundida en las instituciones públicas y privadas, con el objetivo de minimizar el desperdicio de materiales, medicamentos, equipamientos y recursos humanos. Cabe destacar la importancia del registro del equipo de enfermería, fundamental para el proceso de auditoría. Al profesional enfermero en auditoría compete garantizar la calidad de la asistencia prestada al usuario. Son muchos los desafíos a enfrentar para el desarrollo de la auditoría en enfermería, tales como el descubrimiento de una identidad profesional y la integración con auditores enfermeros de todo el país, entre otros.

Palabras clave: Auditoría de Enfermería; Proceso de Trabajo; Calidad de la Atención de Salud. 


\section{INTRODUÇÃO}

As inovações tecnológicas têm provocado importantes mudanças na área de saúde, constituindo-se um desafio para o enfermeiro, haja vista a necessidade de redefinição de sua função na busca de assegurar seu papel e seu compromisso com a sociedade que, nesse momento, deseja maior qualidade na prestação da assistência à sua saúde ${ }^{(1)}$.

Nesse contexto de mudanças globalizadas se visualizam novas perspectivas para a atuação do Enfermeiro, que deve estar pautada em um saber e um fazer crítico reflexivo, fundamental ao seu desenvolvimento. Nesse sentido, esse profissional precisa ser capaz de enfrentar os desafios da profissão, especificamente no setor gerencial, buscando novas abordagens tais como a gerência participativa e os programas de qualidade, os quais são foco central do trabalho em auditoria.

A auditoria é uma ferramenta gerencial utilizada pelos enfermeiros, para avaliar a qualidade da assistência de enfermagem e os custos gerados pela prestação desta atividade, cujo foco principal é sua dimensão contábil. Identificam-se, na atualidade, maior participação do enfermeiro nas equipes de auditoria. Esse profissional, quando no exercício de suas funções, deve ter visão holística, como qualidade de gestão, qualidade de assistência e quântico-econômico-financeiro, tendo sempre em vista o bem-estar do ser humano enquanto paciente/cliente ${ }^{(2)}$.

Diante disso, este artigo tem o objetivo de fazer uma análise crítico-reflexiva a respeito da auditoria em enfermagem com análise dos limites e possibilidades e seus aspectos teóricos e práticos.

\section{Refletindo sobre o processo de trabalho da auditoria em enfermagem e seus aspectos teórico e prático}

A auditoria em enfermagem tem como finalidade normatizar, orientar, disciplinar, racionalizar e identificar as deficiências existentes nos registros hospitalares, intervindo diretamente nos gastos e glosas desnecessários principalmente nos setores mais críticos como unidade de terapia intensiva, semi-intensiva e centro cirúrgico. É realizada por meio de um conjunto de medidas com o envolvimento de pessoas diretamente ligadas à execução de atividades operacionais nos diferentes setores do hospital, avaliando a sistemática vigente e a qualidade do serviço prestado(3).

Nesse sentido, Motta ${ }^{(4)}$ define auditoria de enfermagem como a avaliação sistemática da assistência de enfermagem prestada ao cliente pela análise dos prontuários, acompanhamento do cliente "in loco" e verificação da compatibilidade entre o procedimento realizado e os itens que compõem a conta hospitalar cobrada, garantindo um pagamento justo mediante a cobrança adequada.

Fonseca et al. ${ }^{(5)}$ afirmam que o objetivo da auditoria de enfermagem é a melhoria da qualidade da assistência de enfermagem que o hospital se propõe a oferecer ao cliente, sendo importante o vínculo entre o setor administrativo da instituição e a enfermagem, no aspecto estrutural e funcional.

A auditoria em enfermagem, na atualidade, é exercida e difundida nas instituições públicas e privadas, objetivando minimizar desperdício de materiais, medicamentos, equipamentos e recursos humanos. No entanto, apesar de ser utilizada principalmente para fins contábeis, traduz-se em benefício não só para a instituição de saúde, uma vez que atinge tanto os pacientes e clientes, como para a própria equipe de enfermagem.

Segundo Scarparo ${ }^{(6)}$, esse tema é pouco explorado no meio científico, evidenciando falta de clareza acerca de concepção, de método e da finalidade da auditoria de enfermagem, requerendo investimentos na produção de conhecimentos que possam sustentar a atuação dos profissionais nessa área.

No entanto, identificou-se que este é um setor em expansão para os enfermeiros, destacando-se dentre outras atividades de auditoria a revisão da conta hospitalar, a qual ocorre por meio da análise dos prontuários, considerado processo necessário para a qualidade do serviço, além de reduzir desperdício de materiais e de medicamentos. Essa análise é realizada por auditores externos e internos, evitando o retrabalho e facilitando as negociações, no que se refere aos efeitos da glosa para operadoras de saúde e unidades referenciadas.

Nesse sentido, ressalta-se a importância do registro da equipe de enfermagem, fundamental ao processo de auditoria, que utiliza como instrumentos o controle e a análise de registros considerado o meio mais seguro para se comprovar e receber o valor gasto da assistência prestada, evitando glosas $^{(7)}$

As glosas são aplicadas quando qualquer situação gerar dúvidas em relação às regras e práticas adotadas pela instituição de saúde, sendo definida como o cancelamento ou recusa parcial ou total, de orçamento e/ou pagamento considerados ilegais ou indevidos, ou seja, está relacionada aos itens que o auditor da operadora de plano de saúde não considera cabível para pagamento ${ }^{(8)}$.

Quando as instituições de cuidado de saúde têm os valores dos serviços prestados glosados pelas operadoras de planos de saúde, elas podem lançar mão de recursos, denominados recursos de glosas, a fim de recuperar suas perdas econômicas $^{(9)}$.

A equipe de enfermagem poderá responder pelas perdas financeiras da instituição auditada, sendo importante que as anotações sejam padronizadas, seguindo uma normativa e levando em consideração aspectos éticos e legais, pois o registro em prontuário faz parte das obrigações legais da enfermagem, devendo qualquer erro ser corrigido de acordo com as normas da instituição.

Dessa forma, é importante identificar na Resolução Cofen $n^{\circ} 191 / 1996^{(2)}$ as normas quanto às anotações de enfermagem, observando o cabeçalho do impresso; as anotações devem ser realizadas em horário e não em turno; observar que a folha de anotação é individualizada; as anotações devem ser realizadas com letra legível, no início do plantão e complementadas durante este; deve seguir uma sequência cefalocaudal; quando tiver erros utilizar os termos "digo", "correção" e nunca corretores ortográficos; utilizar apenas 
siglas padronizadas; e, ao final de cada anotação, conter carimbo, assinatura e número do Conselho Regional do profissional que a realizou.

Quanto à anotação de enfermagem, a Lei 7.498, de 25 de junho de 1986 em seu Art. 14 ${ }^{(10)}$, ressalta a incumbência a todo pessoal de enfermagem da necessidade de anotar no prontuário do paciente todas as atividades da assistência de enfermagem, devendo organizar os documentos referentes ao paciente em relação à Enfermagem ${ }^{(7)}$.

A auditoria em enfermagem pode ser entendida como uma avaliação sistemática da assistência de enfermagem, verificada através das anotações de enfermagem no prontuário dos pacientes e/ou das próprias condições destes ${ }^{(5)}$. Poderá ser realizada em hospitais, clínicas, ambulatórios e operadoras de planos de saúde, estando inter-relacionada com todas as outras áreas da empresa à qual esteja vinculada.

A auditoria na área hospitalar poderá ser utilizada ainda como instrumento de desempenho gerencial, avaliando a assistência e proporcionando desenvolvimento profissional e científico da enfermagem. É importante ressaltar que as atribuições do auditor não devem restringir-se à análise dos prontuários, tornando por vezes este profissional como um mero tarefeiro, é fundamental que desenvolva habilidades técnicas, políticas e científicas, por meio de trabalhos científicos e ensaios sobre o processo de trabalho nessa área.

Enfatizando a importância da auditoria de enfermagem, Chinaglia(3) $^{(3)}$ irma que a necessidade de uma auditoria surge a partir dos problemas ocorridos dentro de setores considerados críticos no hospital como centro cirúrgico, unidade de terapia intensivo e setor de semi-intensivos. No centro cirúrgico, por ser um setor fechado e de custo elevado; nas unidades de terapia intensivas ou semi-intensivas, devido à média de permanência prolongada e nas unidades de internação, a grande rotatividade contribui para perdas. A falta de auditoria acarreta em glosas de convênios, cobranças incorretas, seja para mais ou para menos, gerando situações desagradáveis e perdas financeiras.

Faz-se necessário que o enfermeiro desenvolva um olhar crítico sobre a assistência prestada, realizando análise comparativa dos tipos de assistência oferecida entre prestadores com perfis de prestação de serviço semelhante, analisando as tabelas utilizadas e conhecendo os contratos firmados entre instituições que auditam e são auditadas, desenvolvendo e aprimorando a auditoria de enfermagem.

A visita técnica ao prestador ou à unidade de referência que deverá ser auditada é fundamental, pois oportuniza a observação do trabalho operacional do prestador, bem como permite esclarecer dúvidas, sendo importante o agendamento prévio e uniformização das decisões perante os diversos prestadores, devendo ser observadas questões éticas e as responsabilidades junto à instituição e aos usuários, que deve ser pautada na confiança individual e institucional, na imagem do auditor e na credibilidade.

Ao profissional enfermeiro em auditoria compete a garantia da qualidade da assistência prestada ao usuário, proporcionando-Ihe confiabilidade e segurança na relação; viabilizar economicamente a empresa; efetuar levantamento dos custos assistenciais para determinar metas gerenciais e subsidiar decisões do corpo diretivo da empresa; fazer provisão e adequação dos materiais utilizados; conferir a correta utilização/cobrança dos recursos técnicos disponíveis; educar a operadora e os prestadores de serviços; proporcionar um espaço de diálogo permanente entre o prestador e a empresa e prestador/ empresa/usuário.

Quanto ao perfil, o auditor em enfermagem deverá possuir conhecimento técnico, saber ouvir e calar quando necessário, tendo sempre sigilo e discrição, autonomia e independência; domínio do julgamento profissional; imparcialidade e objetividade.

\section{CONCLUSÃO}

São muitos os desafios a enfrentar para o desenvolvimento da auditoria em enfermagem, tais como a descoberta de uma identidade profissional; a integração com auditores enfermeiros de todo o país, em associações; o desenvolvimento de uma visão de conjunto da auditoria em saúde, ampliando a integração com outros auditores; reconhecimento dos diferentes atores que surgem no mercado de auditoria em saúde, respeitando a esfera de atuação desses profissionais e articulando-se de forma interdisciplinar; aprofundar conhecimento, buscando a essência da auditoria.

\section{REFERÊNCIAS}

1. Simões ALA, Fávero N. Aprendizagem da liderança: opinião de enfermeiros sobre a formação acadêmica. Rev Latino-am. Enferm 2000;8(3):91-6.

2. Conselho Federal de Enfermagem (Brasil) Resolução do COFEN-266/2001, de 5 de outubro de 2011. Aprova atividades de enfermeiro auditor. [resolução na internet]. Diário Oficial da União 5 out de 2011 [acesso em: 26 jan 2007]. Disponível em: < http://site.portalcofen.gov. br/node/4303>.

3. Chinaglia K. A importância da Auditoria de Enfermagem para as Instituições de Saúde. [monografia na internet];
2008 [acesso em 26 jan 2007]. Disponível em: < http:// www.mhariolincoln.jor.br/index $>$.

4. Motta ALC. Auditoria de Enfermagem nos Hospitais e Operadoras de Planos de Saúde. 4. ed. São Paulo: látria; 2008. p. 166.

5. Fonseca AS, Yamanaka NMA, Barison THS, Luz SF. Auditoria e o uso de indicadores assistenciais: uma relação mais que necessária para a gestão assistencial na atividade hospitalar. Mundo da Saúde 2005; 29(2):161-9.

6. Scarparo AF. Auditoria em enfermagem: revisão de literatura. Rev Nurs 2005;80(8):46-50. 
7. Ito EE, Senes AM, Santos MAM, Gazzi O; Martins SAS. Manual de anotação de Enfermagem. São Paulo: Atheneu; 2004.

8. Pellegrini G. Auditoria em faturamento. In: Anais eletrônicos do $15^{\circ}$ Congresso Latino Americano de Serviços de Saúde e $3^{\text {a }}$ Jornada de Gestão e Clínicas Médicas; 2004; São Paulo, Brasil. São Paulo; 2004.

9. Rodrigues VA, Perroca MG, Jericó MC. Glosas hospitalares: importância das anotações de enfermagem. Arq Ciênc Saúde 2004;11(4):210-4.

10. Conselho Federal de Enfermagem (Brasil). Resolução Cofen $n^{\circ} 191$, de 31 de maio 1996. Dispõe sobre a forma de anotação e o uso do número de inscrição ou da autorização, pelo pessoal de Enfermagem [resolução na internet]. Diário Oficial da União 31 maio 1996. [acesso em 26 jan 2007]. Disponível em: <http://www.portalcofen.gov. $\mathrm{br} / 2007 /$ materias.asp?ArticleID $=7038 \&$ sectionID $=34>$. 